\title{
Knockdown of long non-coding RNA DLEU2 suppresses idiopathic pulmonary fibrosis by regulating the microRNA-369-3p/TRIM2 axis
}

\author{
HENGZHONG YI ${ }^{1}$, DANLIN LUO ${ }^{1}$, YANGBAO XIAO $^{2}$ and DI JIANG ${ }^{3}$ \\ ${ }^{1}$ Sixth Medical Department, ${ }^{2}$ Endoscopy Center, Hunan Chest Hospital, Changsha, Hunan 410013; \\ ${ }^{3}$ Department of Ultrasound, The First Affiliated Hospital of University of South China, Hengyang, Hunan 421001, P.R. China
}

Received November 23, 2020; Accepted February 8, 2021

DOI: $10.3892 /$ ijmm.2021.4913

\begin{abstract}
Idiopathic pulmonary fibrosis (IPF) is the most common form of idiopathic interstitial pneumonia with an increasing incidence. In the present study, Genome Expression Omnibus (GEO) datasets (GSE10667, GSE24206 and GSE32537) were applied to identify lncRNA DLEU2 in IPF. Through prediction using starBase, TargetScan, miRTarBase and miRDB, tripartite motif containing 2 (TRIM2) and prostaglandin F2 receptor inhibitor (PTGFRN) were found to be upregulated in IPF. DLEU2 expression, the mRNA expression of TRIM2 and PTGFRN, and miR-369-3p expression in A549 cells and lung tissues were detected by RT-qPCR. The protein expression of TRIM2 and PTGFRN in lung tissues and A549 cells was detected by western blot analysis. The proliferation and migration of A549 cells was respectively detected by CCK-8 assay and wound healing assay. The expression of collagen I, $\alpha$-smooth muscle actin (SMA) and E-cadherin was detected by immunofluorescence assay in A549 cells, and collagen I expression was detected by immunohistochemistry assay in lung tissues. The expression of collagen I, $\alpha$-SMA and E-cadherin was also detected by western blot analysis in A549 cells and lung tissues. Dual-luciferase reporter assay was used to confirm the association between DLEU2 and miR-369-3p, and miR-369-3p and TRIM2. As a result, DLEU2 expression was found to be upregulated in IPF and in transforming growth factor (TGF)- $\beta 1$-stimulated A549 cells. The silencing of DLEU2 inhibited the TGF- $\beta 1$-induced proliferation, migration and epithelial-mesenchymal transition (EMT) of A549 cells and bleomycin (BLM)-induced pulmonary fibrosis in mice. TRIM2 expression was increased and miR-369-3p expression was decreased in the lung tissues of mice with BLM-induced
\end{abstract}

Correspondence to: Dr Di Jiang, Department of Ultrasound, The First Affiliated Hospital of University of South China, 69 Chuanshan Road, Shigu, Hengyang, Hunan 421001, P.R. China

E-mail: jiangdijjdd@163.com

Key words: lncRNA DLEU2, miR-369-3p, tripartite motif containing 2, idiopathic pulmonary fibrosis fibrosis and in TGF- $\beta 1$-stimulated A549 cells. DLEU2 directly targeted miR-369-3p. The effect of the silencing of DLEU2 on TGF- $\beta 1$-stimulated A549 cells was suppressed by the silencing of miR-369-3p. TRIM2 was the target protein of miR-369-3p. On the whole, the present study demonstrates that the silencing of DLEU2 suppressed IPF by upregulating miR-369-3p expression and downregulating TRIM2 expression.

\section{Introduction}

Idiopathic pulmonary fibrosis (IPF) is a slow progressive lung interstitial disease, with an unknown cause. The risk factors for IPF include age, sex, exposure to metal and wood chips, and a history of smoking (1). The histopathological manifestation of IPF is a common type of interstitial pneumonia, characterized by the remodeling of lung tissue, including the excessive proliferation of fibroblasts and the deposition of large amounts of collagen (2). IPF is also considered to be an age-related disease. The age of the patients is generally $>60$ years and the majority are male. In the absence of lung transplantation, the median survival time of patients is $3-5$ years from the date of diagnosis (3). At present, the specific pathogenesis of IPF remains unclear; therefore, IPF is difficult to diagnose and the identification of novel methods for the diagnosis and treatment of this respiratory disease is a hot research topic.

With the rapid development of whole-genome next-generation sequencing, long non-coding RNAs (lncRNAs) have been found to have a variety of biological functions, based on their conserved secondary or tertiary structure (4). At present, lncRNAs are defined as a large number of different types of transcriptional RNA molecules that lack an open reading frame and are $>200$ nucleotides in length (5). The expression level of DLEU2 has been found to be increased in non-small cell lung cancer (NSCLC) tissues and is associated with a poor survival and tumor recurrence, while the downregulation of DLEU2 can partially reverse tumorigenesis (6). The DLEU2 expression level has been shown to be elevated in osteosarcoma tissues and cells, and the downregulation of DLEU2 suppresses cell viability and migration (7). In cervical cancer tissues, DLEU2 expression has been found to be increased; the silencing of DLEU2 has been shown to block cell proliferation and cell cycle progression, increased the rate of apoptosis in 
cervical cancer cells in vitro, and inhibit tumor development in vivo (8).

However, to the best of our knowledge, the role of DLEU2 in IPF has not been reported to date. In the present study, the Genome Expression Omnibus (GEO) database was used to download 3 IPF-related datasets (GSE10667, GSE24206 and GSE32537), and it was observed that the DLEU2 expression level was increased in IPF lung tissues.

The microRNAs (miRNAs/miRs) that were found to interact with DLEU2 were predicted using the starBase database, and the mRNAs that could bind to the aforementioned miRNAs were identified using the TargetScan, miRTarBase and miRDB online tools. The identified mRNAs and the upregulated mRNAs in the GSE10667, GSE24206 and GSE32537 datasets were intersected to obtain the target genes, tripartite motif containing 2 (TRIM2) and prostaglandin F2 receptor inhibitor (PTGFRN). Following the preliminary experiment, the effect of DLEU2 downregulation on the TRIM2 mRNA expression level was more prominent compared with that on PTGFRN mRNA expression. A previous study demonstrated that TRIM2 was predicted to regulate the ubiquitination of vimentin in lung squamous cell carcinoma cell lines (9). Furthermore, TRIM2 has been shown to promote the growth, invasion and metastasis of colorectal cancer cells through epithelial-mesenchymal transition (EMT) (10). In addition, TRIM2 has been found to promote the occurrence and metastasis of osteosarcoma through the PI3K/KPB signaling pathway (11). Both DLEU2 and TRIM2 interact with miR-369-3p. However, the mechanisms through which DLEU2 regulates IPF through the miR-369-3p/DLEU2 pathway remain unknown and are worthy of investigation.

Therefore, the aim of the present study was to investigate the role of the DLEU2/miR-369-3p/TRIM2 axis in IPF.

\section{Materials and methods}

Data extraction. The microRNAs (miRNAs/miRs) that were found to interact with DLEU2 were predicted using the starBase database (http://starbase.sysu.edu.cn/index.php), and the mRNAs that could bind to the aforementioned miRNAs were identified using the TargetScan (http://www.targetscan. org/vert_72/), miRTarBase (http://mirtarbase.mbc.nctu.edu. tw/index.html) and miRDB (http://www.mirdb.org/) online tools. The raw microarray data were retrieved from the GEO database using the accession numbers GSE10667, GSE24206 and GSE32537.

Xenograft model of pulmonary fibrosis. A total of 40 male C57BL/6 mice (6-8 weeks old) were provided from the Beijing Vital River Laboratory Animal Technology Co., Ltd. Mice were housed in an environmentally controlled room $\left(22 \pm 2^{\circ} \mathrm{C}\right.$; $12 \mathrm{~h}$ light-12 h dark cycle; $50-60 \%$ humidity) and free access to food and water. A mouse model of bleomycin (BLM)-induced pulmonary fibrosis was established as described in a previous study (12). Each group included 10 mice. Mice in the BLM group were stimulated by an intratracheal instillation of BLM (1.5 U/kg body weight), while mice in the control group were injected with an equal volume of physiological saline. In the BLM + short hairpin (sh)RNA-negative control (NC) and the BLM + shRNA-DLEU2 groups, the mice were injected intratracheally with a lentivirus suspension of shRNA-NC or shRNA-DLEU2 (3x10 7 transducing units/mouse), respectively, 3 days following the administration of BLM. Furthermore, mice in the BLM group were treated by injecting the same volume of physiological saline into the trachea. During the process of intratracheal instillation and intratracheal transfection, mice were anesthetized by an intraperitoneal injection of sodium pentobarbital $(50 \mathrm{mg} / \mathrm{kg})$. After 28 days, the mice were euthanized by an intraperitoneal injection of sodium pentobarbital $(200 \mathrm{mg} / \mathrm{kg})$, and the lung tissues were collected for subsequent analysis. All the experiments were approved and supervised by the Animal Care and Use Committee and the Animal Ethics Committee at University of South China.

Cells, cell culture and induction. The human A549 alveolar epithelial cell line (ATCC ${ }^{\circledR}$ CCL-185 ${ }^{\mathrm{TM}}$ ) was purchased from the American Type Culture Collection (ATTC) and routinely cultured in high-glucose DMEM, containing 10\% FBS (Gibco; Thermo Fisher Scientific, Inc.), $100 \mathrm{U} / \mathrm{ml}$ penicillium and $100 \mathrm{~g} / \mathrm{ml}$ streptomycin in a cell incubator $\left(37^{\circ} \mathrm{C}\right.$ and $\left.5 \% \mathrm{CO}_{2}\right)$. When the cell confluency reached $80 \%$, the A549 cells were stimulated with transforming growth factor (TGF)- $\beta 1$ (10 ng/ml) for $48 \mathrm{~h}$.

Reverse transcription-quantitative PCR (RT-qPCR) analysis. Total RNA was extracted from the lung tissues and the A549 cells using TRIzol ${ }^{\circledR}$ reagent (Thermo Fisher Scientific, Inc.). The lung tissue was ground into a suspension using a homogenizer. A total of $50 \mathrm{mg} / \mathrm{ml} \mathrm{TRIzol}{ }^{\circledR}$ was added to the suspension and centrifuged at $3,000 \mathrm{x}$ g for $15 \mathrm{~min}$ at $4^{\circ} \mathrm{C}$ to obtain the supernatant. The A549 cells were digested with $1 \mathrm{ml} \mathrm{TRIzol}{ }^{\circledR}$ at room temperature for $5 \mathrm{~min}$, then centrifuged at $3,000 \mathrm{x} \mathrm{g}$ for $15 \mathrm{~min}$ at $4^{\circ} \mathrm{C}$ to obtain the supernatant. The supernatant was then added to isopropyl alcohol with sufficient mixing, then centrifuged at $3,000 \mathrm{x}$ g for $10 \mathrm{~min}$ at $4^{\circ} \mathrm{C}$ to discard the supernatant. The precipitate was washed with anhydrous ethyl alcohol, then added to diethyl pyrocarbonate water to measure the RNA concentration (ng/ $\mu \mathrm{l})$. Reverse transcription was performed using the cDNA RT kit (Roche Molecular Diagnostics) and qPCR was performed using the SYBR-Green Fast qPCR mix (Beyotime Institute of Biotechnology). The thermocycling condition were as follows: Initial denaturation at $95^{\circ} \mathrm{C}$ for $25 \mathrm{sec}$; followed by 40 cycles of $90^{\circ} \mathrm{C}$ for $30 \mathrm{sec}$, $55^{\circ} \mathrm{C}$ for $35 \mathrm{sec}$ and $72^{\circ} \mathrm{C}$ for $35 \mathrm{sec}$. The following primer pairs were used for the qPCR: DLEU2 forward, 5'-TCCGAG AGTATAGCGCCACT-3' and reverse, 5'-ACTGCCCTTTGC TCCAAGTA-3'; TRIM2 forward, 5'-TGGAGAAGGAAA TGGGCATG-3' and reverse, 5'-CTGCAACCACAACATGCA CCA-3';PTGFRN forward, 5'-CTTCAGCAGGATGCCTGA CA-3' and reverse, 5'-CACCAGGGAATCACGGTCAA-3'; GAPDH forward, 5'-AAGGTGAAGGTCGGAGTCAAC-3' and reverse, 5'-GGGGTCATTGATGGCAACAATA-3'; miR-369-3p 5'-GGGACCCAGTTCAAGTAATTCAGG-3' and reverse, 5'-TTTGGCACTAGCACATT-3'; U6 forward, 5'-CTCGCTTCGGCAGCACA-3' and reverse, 5'-AACGCT TCACGAATTTGCGT-3'. RNA levels were quantified using the $2^{-\Delta \Delta \mathrm{Cq}}$ method (13).

Cell transfection. A549 cells in the logarithmic growth phase were cultured overnight in 6-well plates. Subsequently, $5 \mathrm{nM}$ 
shRNA-NC, $5 \mathrm{nM}$ shRNA-DLEU2-1/2, $5 \mathrm{nM}$ mimic-NC, $5 \mathrm{nM}$ miR-369-3p mimic, $5 \mathrm{nM}$ inhibitor-NC and $5 \mathrm{nM}$ miR-369-3p inhibitor were transfected into the A549 cells using Lipofectamine ${ }^{\circledR} 2000$ (Invitrogen; Thermo Fisher Scientifc, Inc.), and incubated for $24 \mathrm{~h}$ at $37^{\circ} \mathrm{C}$. The culture medium was changed every $6 \mathrm{~h}$. The supplier of the shRNAs, controls, mimics and inhibitors were RiboBio (https://www. ribobio.com/).

Cell Counting jkt (CCK)-8 assay. The experiment was performed using a 96 -well cell culture plate $(3,000$ cells/well), and the A549 cells in each group were measured at 24, 48 and $72 \mathrm{~h}$. Following stimulation with TGF- $\beta 1$ induction and/or cell transfection for $48 \mathrm{~h}, 10 \mu \mathrm{l}$ CCK-8 solution were added to each well followed by incubation at $37^{\circ} \mathrm{C}$ for $2 \mathrm{~h}$. The absorbance of each group was determined using a Multiskan FC photometer (Thermo Fisher Scientific, Inc.) at $450 \mathrm{~nm}$.

Wound healing assay. After TGF- $\beta 1$ induction and/or cell transfection, the A549 cells were cultured in 6-well plates overnight. The cell monolayers were scratched vertically with a 200- $\mu 1$ micropipette tip. Serum-free medium was then added to the cells, which were incubated in an incubator at $37^{\circ} \mathrm{C}$ with $5 \% \mathrm{CO}_{2}$ for $24 \mathrm{~h}$. Images were then captured under a light microscope (Olympus Corporation) at a magnification of x100 and analyzed using ImageJ software (v1.8.0; National Institutes of Health).

Immunofluorescence assay. A549 cells in the logarithmic growth phase were collected and $\sim 1 \times 10^{5}$ cells/per well were placed in immunofluorescence dishes until they had adhered to the plate. The old culture medium was discarded. Following TGF- $\beta 1$ stimulation and/or cell transfection for $48 \mathrm{~h}$, the A549 cells were washed with pre-cooled PBS and fixed with $4 \%$ paraformaldehyde for $10 \mathrm{~min}$ at room temperature. After washing with PBS, the A549 cells were permeated for $10 \mathrm{~min}$ with $0.5 \%$ Triton X-100 at room temperature. Normal goat serum was added into the dish and incubated at room temperature for $30 \mathrm{~min}$. After the blocking reagent was discarded, the appropriate primary antibodies collagen I (ab260043; 1:250; Abcam), $\alpha$-SMA (ab124964; 1:250; Abcam) and E-cadherin (ab40772; 1:500; Abcam) were added to each dish and placed in a wet box for incubation at $4{ }^{\circ} \mathrm{C}$ overnight. The cells were then incubated at room temperature for $1 \mathrm{~h}$ in a wet box with a fluorescent secondary antibody (goat anti-rabbit IgG H\&L; Alexa Fluor ${ }^{\circledR}$ 488; dilution, 1:500; ab150077; Abcam). DAPI was added to the A549 cells and incubated for $5 \mathrm{~min}$ in the dark to stain the cell nuclei. Anti-fluorescence quenching agent was added to the dishes, and images were then captured using an inverted fluorescence microscope (Olympus Corporation) at a magnification of $\mathrm{x} 200$.

Western blot analysis. Total protein was extracted from the lung tissue and the A549 cells using RIPA lysis buffer (Beyotime Institute of Biotechnology) with protease inhibitor, then centrifuged at $3,000 \mathrm{x} \mathrm{g}$ at $4^{\circ} \mathrm{C}$ for $10 \mathrm{~min}$ to obtain the supernatant, which was subsequently stored at $-20^{\circ} \mathrm{C}$ until further use. BCA assay (Abcam) was used for protein determination. Protein lysates $(30 \mu \mathrm{g})$ of each group were separated using 10\% SDS-PAGE, transferred to a PVDF membrane and blocked with TBS-Tween-20 (0.1\%), containing 5\% bovine serum albumin (Gibco; Thermo Fisher Scientifc, Inc.) for $1 \mathrm{~h}$ at room temperature. TBST was used to dilute the primary antibodies containing collagen I (ab34710; Abcam), $\alpha$-SMA (\#19245; Cell Signaling Technology, Inc.), E-cadherin (ab76055; Abcam), TRIM2 (ab3942; Abcam), PTGFRN (ab97567; Abcam) and GAPDH (ab8245; Abcam) at a 1:1,000 dilution, which were then added to the membrane for overnight incubation at $4^{\circ} \mathrm{C}$. The PVDF membrane was washed with TBST 3 times, for 10 min each time. Subsequently, anti-rabbit IgG-HRP secondary antibody (\#7074; dilution,1:1,000; Cell Signaling Technology, Inc.), diluted with TBST at 1:1,000, was added to the membrane and incubated at room temperature for $1 \mathrm{~h}$. The PVDF membrane was then washed with TBST and the protein bands were visualized using an enhanced chemiluminescence reagent. The protein bands were imaged using an iBright CL1500 Imaging System (Invitrogen; Thermo Fisher Scientific, Inc.). Image-Pro Plus software (version 6.0; Media Cybernetics, Inc.) was used for densitometry.

Hematoxylin and eosin $(H \& E)$ and Masson's trichrome staining. Following euthanasia, the left lung was dissected, washed with iso-osmotic saline and pressed between 2 filter papers. The dried lungs were preserved in a $10 \%$ formalin, dehydrated with a gradient concentration of ethanol and embedded in paraffin. The paraffin block was fixed on the slicer and cut into 5- $\mu \mathrm{m}$-thick sections, affixed to the slides, and placed in a $45^{\circ} \mathrm{C}$ thermostat to dry. Pathological staining of the lung tissue was performed according to the instructions of the H\&E (Beyotime Institue of Biotechnology) and Masson kits (Beyotime Institue of Biotechnology) at a magnification of $x 400$ (14).

Immunohistochemistry. Lung tissue samples embedded in paraffin were rehydrated and incubated with the anti-collagen I primary antibody (dilution, 1:100; ab270993; Abcam) at $4^{\circ} \mathrm{C}$ overnight. After washing, the slides were incubated with the anti-mouse IgG-HRP secondary antibody (dilution, 1:100; ab6728; Abcam) at $37^{\circ} \mathrm{C}$ for $20 \mathrm{~min}$. Lung tissue specimens were counterstained with hematoxylin at room temperature for $1 \mathrm{~min}$ and mounted with neutral balsam. The staining extent and intensity were observed under an optical microscope (Olympus Corporation) at a magnification of $\mathrm{x} 400$ and evaluated as previously described (15).

Dual-luciferase reporter assay. To verify whether DLEU2 can bind to miR-369-3p, the A549 cells were co-transfected with the DLEU2 3'-untranslated region (UTR) pmirGLO plasmid [containing wild-type (WT) DLEU2 3'-UTR or mutant (MUT) DLEU2 3'-UTR] and miR-369-3p mimic or mimic-NC using Lipofectamine ${ }^{\circledR} 2000$. In addition, to verify whether miR-369-3p can bind to TRIM2, the A549 cells were co-transfected with TRIM2 3'-UTR pmirGLO plasmid (containing WT TRIM2 3'UTR or MUT TRIM2 3'-UTR) and miR-369-3p mimic or mimic-NC using Lipofectamine ${ }^{\circledR} 2000$. The relative luciferase (R-Luc) activity was detected using a dual-luciferase assay system (Promega Corporation), which was normalized to Renilla luciferase activity following transfection for $24 \mathrm{~h}$. The pmirGLO plasmid, mimics and inhibitors were obtained from Guangzhou RiboBio Co., Ltd. 
A

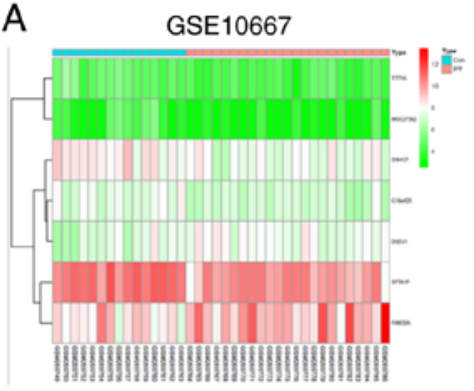

B

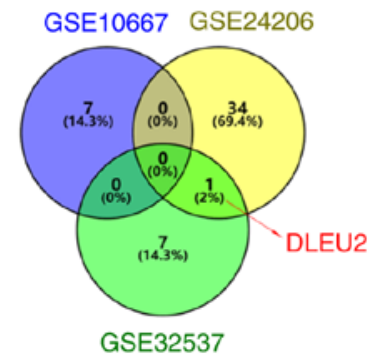

GSE24206

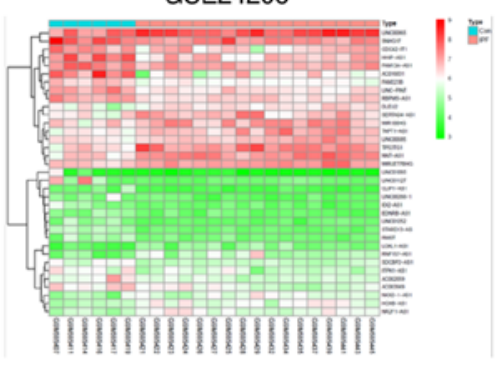

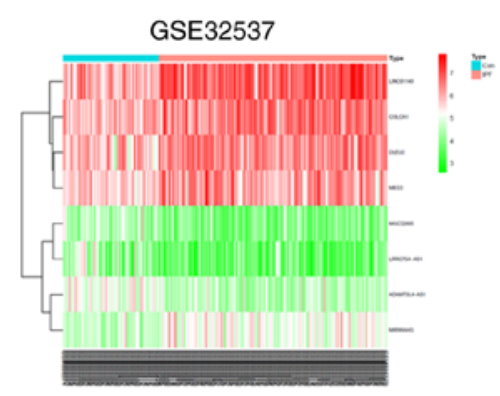

GSE32537

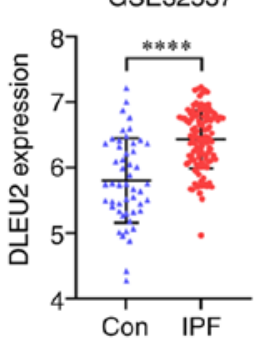

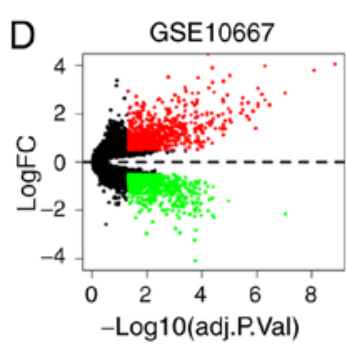

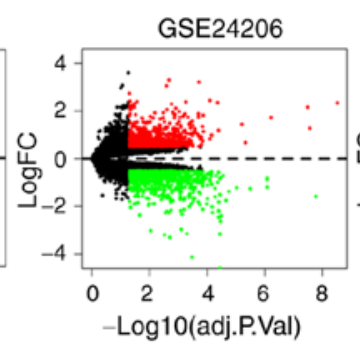

GSE24206

F
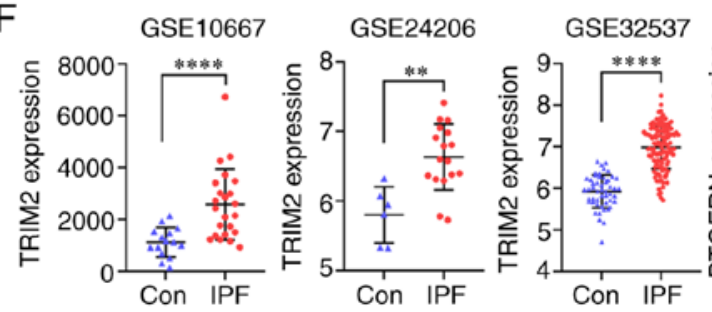

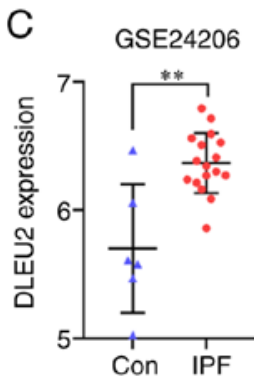

E
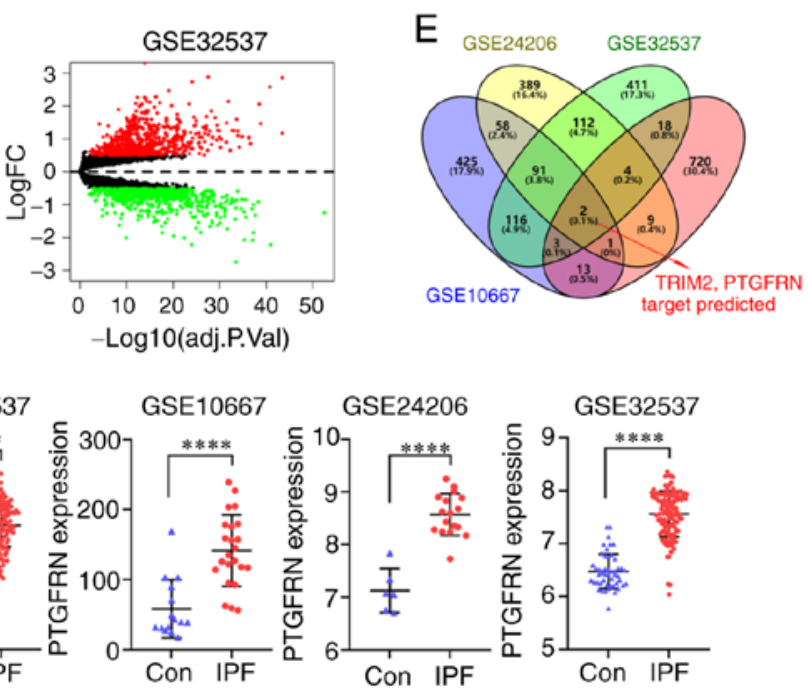

Figure 1. DLEU2 expression is upregulated in pulmonary fibrosis. (A) Differentially expressed lncRNAs screened from IPF related datasets (GSE10667, GSE24206 and GSE32537) ( $\operatorname{logFC}=0.5)$. (B) The intersection of differentially expressed lncRNAs in IPF related data sets is illustrated by the Venn diagram. (C) DLEU2 expression was increased in the lung tissues of patients with IPF. (D) Differentially expressed mRNAs screened from IPF related data sets (GSE10667, GSE24206 and GSE32537). (E) The intersection of upregulated mRNAs from IPF-related datasets and predicted mRNAs shown by the Venn diagram. (F) The expression of TRIM2 and PTGFRN was increased in the lung tissues of patients with IPF. ${ }^{* *} \mathrm{P}<0.01$ and ${ }^{* * * *} \mathrm{P}<0.0001$ vs. control (Con) group. IPF, idiopathic pulmonary fibrosis; TRIM2, tripartite motif containing 2; PTGFRN, prostaglandin F2 receptor inhibitor.

Statistical analysis. SPSS v19.0 software (SPSS, Inc.) was used for statistical analysis, and the data are presented as the means \pm standard deviation. The differences between multiple groups were analyzed using one-way ANOVA followed by Tukey's post hoc test. The differences between 2 groups were analyzed using a Student's t-test. $\mathrm{P}<0.05$ was considered to indicate a statistically significant difference.

\section{Results}

DLEU2 expression is increased in pulmonary fibrosis. The IPF datasets (GSE10667, GSE24206 and GSE32537) were downloaded from the GEO database and used to identify the differentially expressed lncRNAs (log fold change, 0.5) (Fig. 1A). One of the differentially expressed lncRNAs identified from the 3 datasets was DLEU2 (Fig. 1B). The DLEU2 expression level was increased in the IPF group, which was found in the GSE24206 and GSE32537 datasets (Fig. 1C). The differentially expressed mRNAs were also identified from the 3 datasets (Fig. 1D). The miRNAs that were found to interact with DLEU2 were predicted using the starBase database, and the mRNAs that could bind to the identified miRNAs were predicted using the TargetScan, miRTarBase and miRDB databases. The identified mRNAs and upregulated mRNAs in the 3 datasets were intersected, and the target genes TRIM2 and PTGFRN were identified (Fig. 1E). The expression level of TRIM 2 and PTGFRN was increased in the IPF group, which was found in all 3 datasets (Fig. 1F). 
A

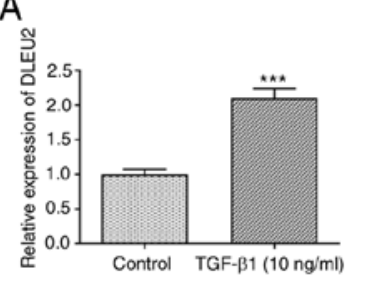

C

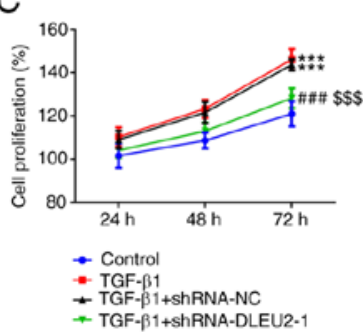

G
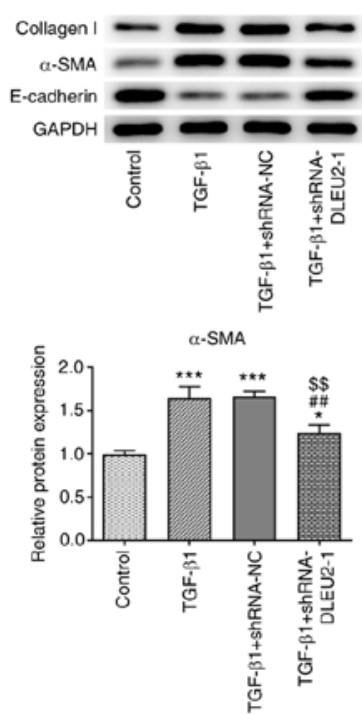

B
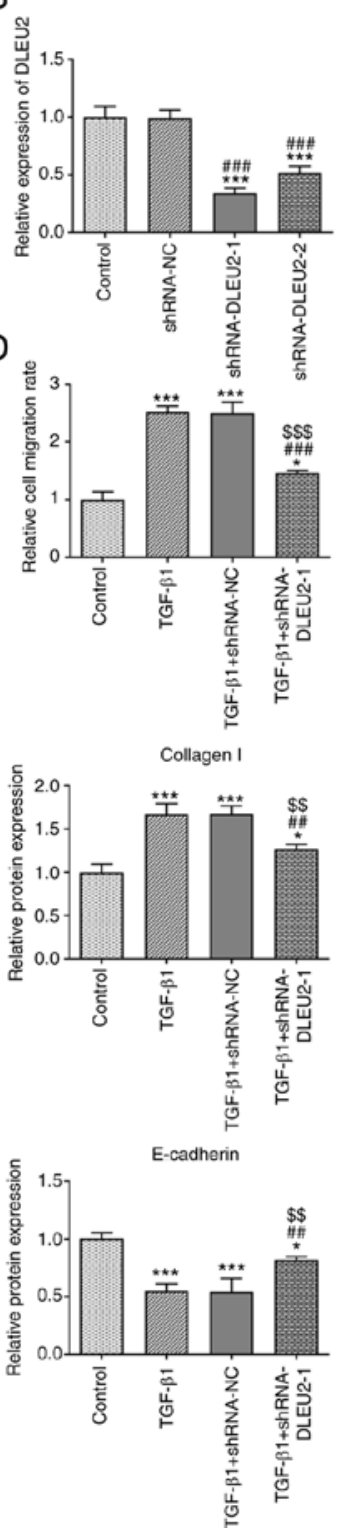

E

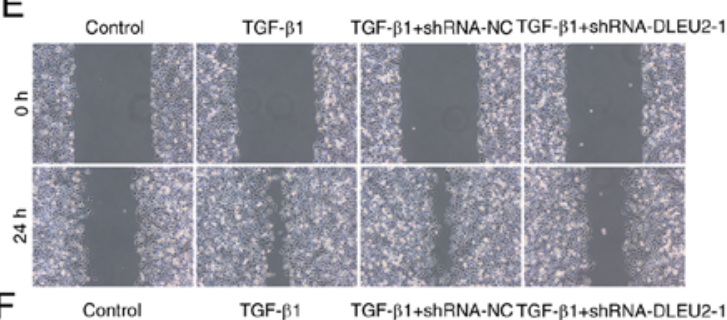

F
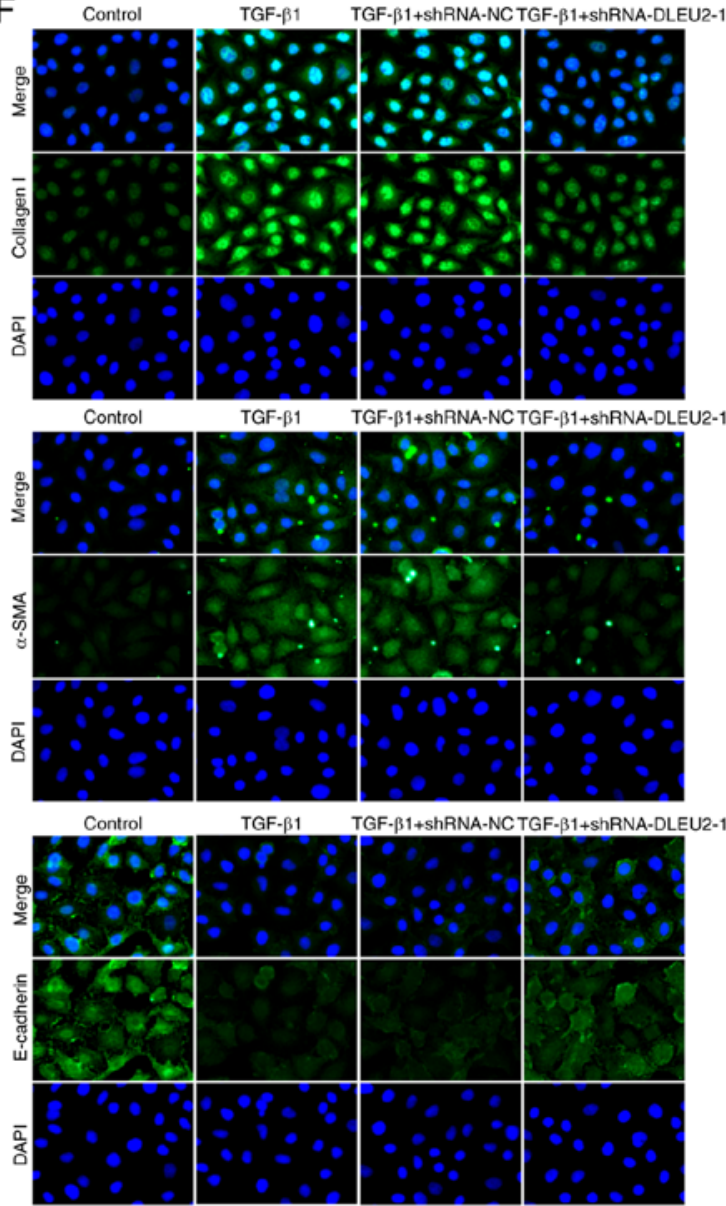

GF- $\beta 1+$ ShRNA-NCTGF- $\beta 1+$ shRNA-DLEU2-1

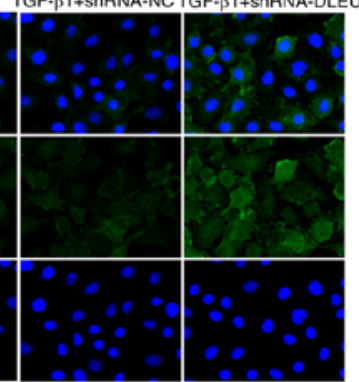

Figure 2. Knockdown of DLEU2 inhibits the TGF- $\beta 1$-induced proliferation, migration and EMT of A549 cells. (A) DLEU2 expression in TGF- $\beta 1$-stimulated A549 cells was detected by RT-qPCR. ${ }^{* * *} \mathrm{P}<0.001$ vs. control group. (B) DLEU2 expression in A549 cells transfected with shRNA-DLEU2-1/2 detected by RT-qPCR. ${ }^{* * *} \mathrm{P}<0.001$ vs. control group; ${ }^{\# \#} \mathrm{P}<0.001$ vs. shRNA-NC group. (C) The proliferation of TGF- $\beta 1$-stimulated A549 cells transfected with shRNA-DLEU2-1 was analyzed by CCK-8 assay. (D and E) The migration of TGF- $\beta 1$-induced A549 cells transfected with shRNA-DLEU2-1 was analyzed by wound healing assay. (F) The expression of collagen I, $\alpha$-SMA and E-cadherin in TGF- $\beta 1$-stimulated A549 cells transfected with shRNA-DLEU2-1 was detected by immunofluorescence assay. (G) The expression of collagen I, $\alpha$-SMA and E-cadherin in TGF- $\beta 1$-stimulated A549 cells transfected with shRNA-DLEU2-1 was detected by western blot analysis. ${ }^{*} \mathrm{P}<0.05$ and ${ }^{* * * *} \mathrm{P}<0.001$ vs. control group; ${ }^{\# \#} \mathrm{P}<0.01$ and ${ }^{\# \# \#} \mathrm{P}<0.001$ vs. TGF- $\beta 1$ group; ${ }^{\$ \$} \mathrm{P}<0.01$ and ${ }^{\$ \$} \mathrm{P}<0.001$ vs. TGF- $\beta 1+$ shRNA-NC group. EMT, epithelial-mesenchymal transition; TGF- $\beta 1$, transforming growth factor $\beta 1 ; \alpha-S M A, \alpha$ smooth muscle actin.

Knockdown of DLEU2 inhibits the TGF- $\beta 1$-induced proliferation, migration and EMT of A549 cells. DLEU2 expression was increased in the TGF- $\beta 1$-stimulated A549 cells (Fig. 2A). Following transfection, DLEU2 expression was decreased in the A549 cells transfected with shRNA-DLEU2-1/2 and DLEU2 expression was lower in the shRNA-DLEU2-1-transfected A549 cells. Therefore, shRNA-DLEU2-1 was selected for use in further experiments (Fig. 2B). TGF- $\beta 1$ promoted the proliferation (Fig. 2C) and migration (Fig. 2D and E) of the A549 cells, which was suppressed by the knockdown of DLEU2. TGF- $\beta 1$ increased the expression levels of collagen I and $\alpha$-SMA, and decreased the expression levels of E-cadherin; these effects were reversed by the knockdown of DLEU2 (Fig. 2G). The results of immunofluorescence assay (Fig. 2F) were consistent with those of the western blot analysis.

Knockdown of DLEU2 attenuates BLM-induced pulmonary fibrosis in mice. BLM contributed to inflammation and pulmonary fibrosis, and increased the expression level of collagen I in the lung tissues, which was alleviated by the knockdown of DLEU2 (Fig. 3A). The protein expression of collagen I and $\alpha$-SMA was also increased, while the expression of E-cadherin was decreased in the lung tissues from mice with BLM-induced fibrosis. The knockdown of DLEU2 was found to reverse these effects (Fig. 3B). BLM also increased the 

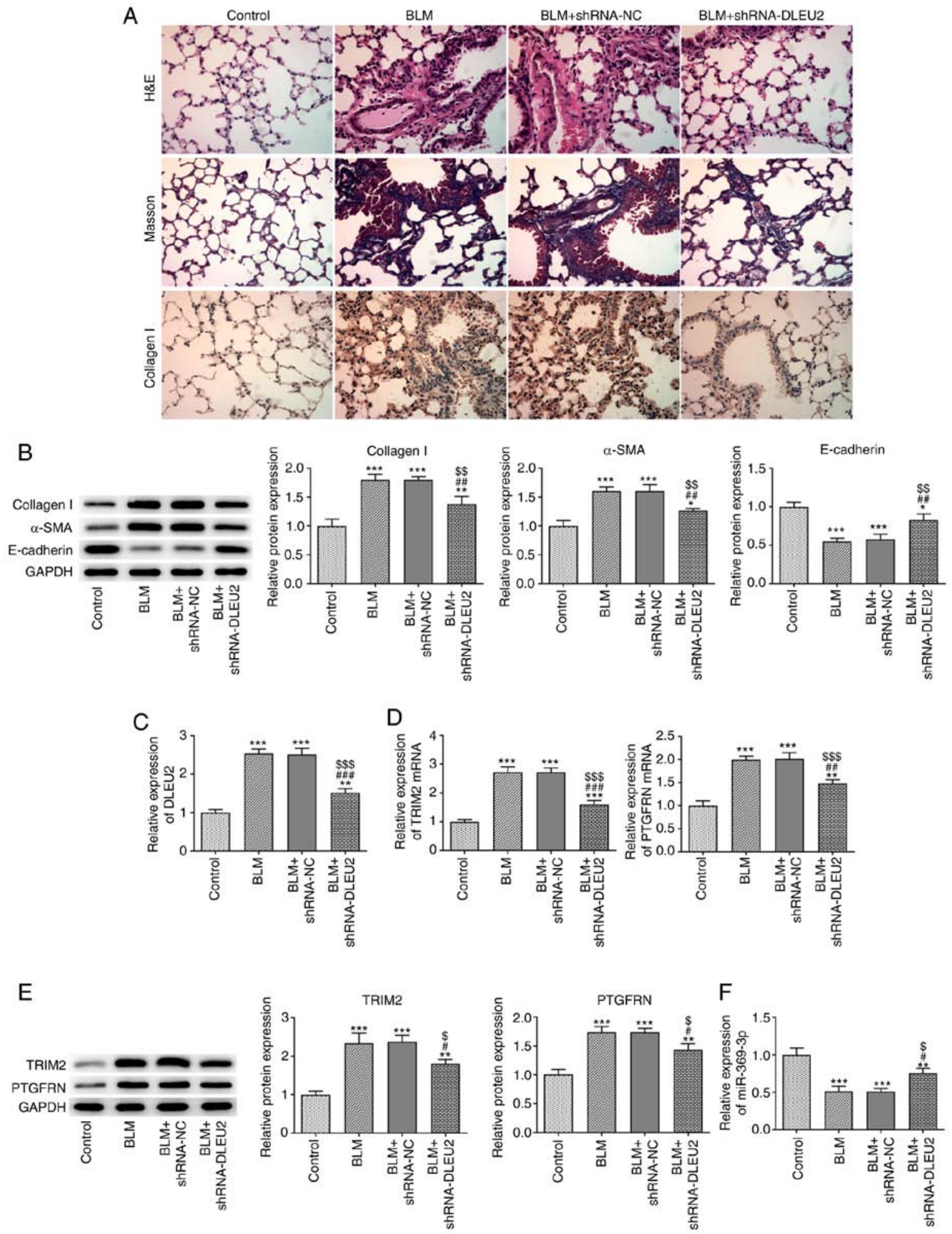

F

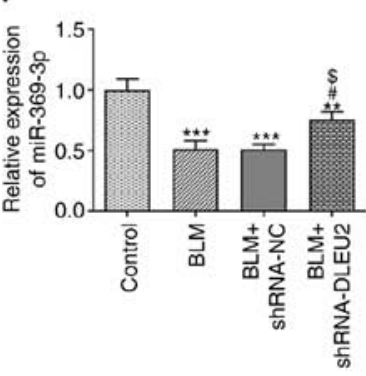

Figure 3. Knockdown of DLEU2 attenuates BLM-induced pulmonary fibrosis in mice. (A) The pathological changes, pulmonary fibrosis and collagen I expression in lung tissues were in turn detected by H\&E staining, Masson's staining and immunohistochemistry. (B) The expression of collagen I, $\alpha$-SMA and E-cadherin in lung tissues of mice with BLM-induced fibrosis following transfection was detected by western blot analysis. (C) DLEU2 expression in lung tissues of mice with BLM-induced fibrosis following transfection was detected by RT-qPCR. (D) The mRNA expression of TRIM2 and PTGFRN in lung tissues of mice with BLM-induced fibrosis following transfection was detected by RT-qPCR. (E) The protein expression of TRIM2 and PTGFRN in lung tissues of mice with BLM-induced fibrosis following transfection was detected by western blot analysis. (F) miR-369-3p expression in lung tissues of mice with BLM-induced fibrosis following transfection was detected by RT-qPCR. ${ }^{*} \mathrm{P}<0.05,{ }^{* *} \mathrm{P}<0.01$ and ${ }^{* * *} \mathrm{P}<0.001$ vs. control group; ${ }^{\#} \mathrm{P}<0.05,{ }^{\# \#} \mathrm{P}<0.01$ and ${ }^{\# \# \#} \mathrm{P}<0.001$ vs. BLM group; ${ }^{\mathrm{S}} \mathrm{P}<0.05,{ }^{\mathrm{SS}} \mathrm{P}<0.01$ and ${ }^{\mathrm{SS}} \mathrm{P}<0.001$ vs. BLM + shRNA-NC group. BLM, bleomycin; TGF- $\beta 1$, transforming growth factor $\beta 1$; $\alpha$-SMA, $\alpha$-smooth muscle actin; TRIM2, tripartite motif containing 2; PTGFRN, prostaglandin F2 receptor inhibitor.

expression levels of DLEU2, TRIM2 and PTGFRN, which were decreased following the knockdown of DLEU2 in lung tissues (Fig. 3C and D). The change in TRIM2 mRNA expression was more significant compared with that in PTGFRN 
A

DLEU2: $5^{\prime}$ cuccuuguuauuUgUaUUAUu $3^{\prime}$

|||||| $\mid$

hsa-miR-369-3p: $3^{\prime}$ uuucuaguugguACAUAAUAa $5^{\prime}$
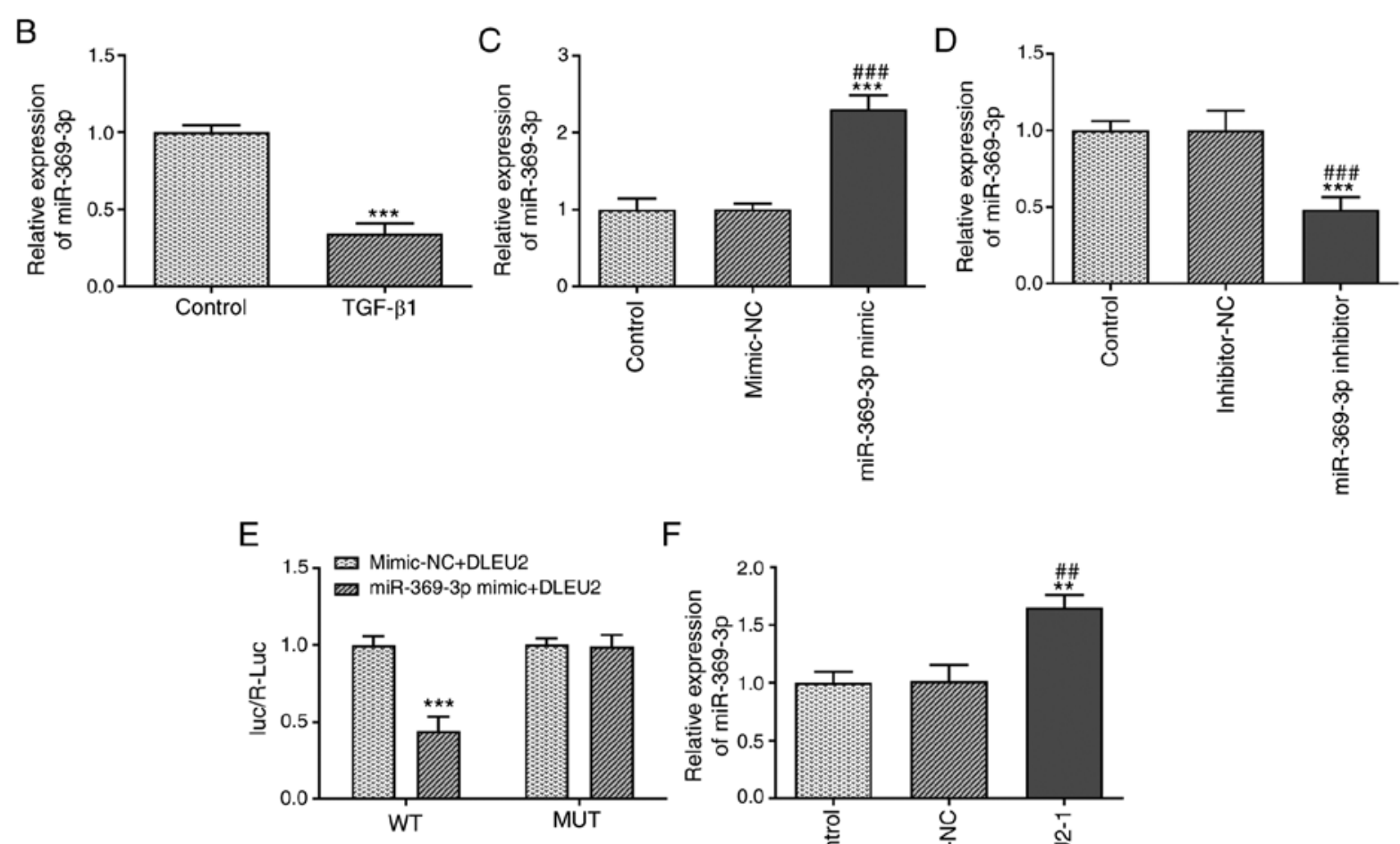

$\mathrm{F}$

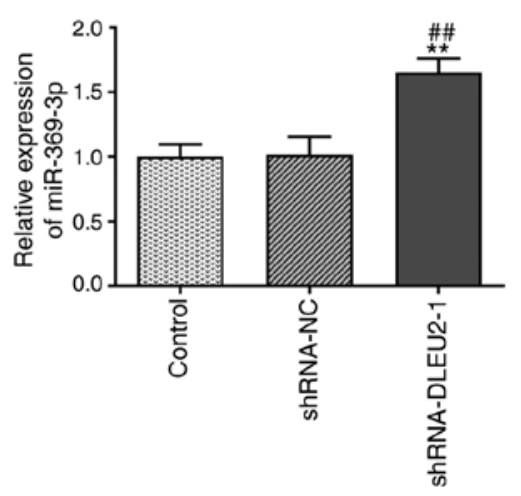

Figure 4. DLEU2 directly targets miR-369-3p. (A) Binding sites between DLEU2 and miR-369-3p. (B) miR-369-3p expression in TGF- 31 -stimulated A549 cells was detected by RT-qPCR. ${ }^{* * *} \mathrm{P}<0.001$ vs. control group. (C) miR-369-3p expression in TGF- $\beta 1$-stimulated A549 cells transfected with miR-369-3p mimic was detected by RT-qPCR. ${ }^{* * *} \mathrm{P}<0.001$ vs. control group. ${ }^{\# \#} \mathrm{P}<0.001$ vs. mimic-NC group. (D) miR-369-3p expression in TGF- $\beta 1$-stimulated A549 cells transfected with miR-369-3p inhibitor was detected by RT-qPCR. ${ }^{* * *} \mathrm{P}<0.001$ vs. control group; ${ }^{\# \#} \mathrm{P}<0.001$ vs. inhibitor-NC group. (E) Luciferase reporter assay for the confirmation of direct binding association between DLEU2 and miR-369-3p. ${ }^{* * *} \mathrm{P}<0.001$ vs. mimic-NC + DLEU2 WT group. (F) miR-369-3p expression in TGF- $\beta 1$-stimulated A549 cells transfected with shRNA-DLEU2-1 was detected by RT-qPCR. ${ }^{* *} \mathrm{P}<0.01$ vs. control group; ${ }^{\# \#} \mathrm{P}<0.01$ vs. shRNA-NC group. TGF- $\beta 1$, transforming growth factor $\beta 1$.

expression following the knockdown of DLEU2 (Fig. 3D). The protein expression levels of TRIM2 and PTGFRN were increased in the lung tissues from mice BLM-induced fibrosis, which were decreased following the knockdown of DLEU2 (Fig. 3E). TRIM2 was selected for analysis in the following experiments. BLM was also found to be associated with a decrease in the mRNA expression level of miR-369-3p in the lung tissues of mice with BLM-induced fibrosis and the knockdown of DLEU2 increased the miR-369-3p expression level (Fig. 3F).

DLEU2 directly targets $m i R-369-3 p$. The binding sites between DLEU2 and miR-369-3p are presented in Fig. 4A. TGF- $\beta 1$ decreased the miR-369-3p expression level in A549 cells (Fig. 4B). The miR-369-3p expression level was increased in the A549 cells transfected with miR-369-3p mimic (Fig. 4C) and decreased in the A549 cells transfected with miR-369-3p inhibitor (Fig. 4D). The Luc/R-Luc value was decreased in the A549 cells co-transfected with miR-369-3p mimics and DLEU2 WT vector (Fig. 4E). In addition, the miR-369-3p expression level was increased in the A549 cells transfected with shRNA-DLEU2-1 (Fig. 4F).
Knockdown of DLEU2 attenuates the growth and invasion of TGF- $\beta 1$-stimulated A549 cells by regulating miR-369-3p. The knockdown of DLEU2 decreased the proliferation (Fig. 5A) and migration (Fig. 5B and C) of the TGF- $\beta 1$-stimulated A549 cells, which was reversed following transfection with the miR-369-3p inhibitor. The knockdown of DLEU2 suppressed the expression levels of collagen I and $\alpha$-SMA, and increased the expression level of E-cadherin in the TGF- $\beta 1$-stimulated A549 cells; these effects were reversed following transfection with the miR-369-3p inhibitor (Fig. 5D). In addition, the knockdown of DLEU2 decreased the mRNA (Fig. 5E) and protein (Fig. 5F) expression level of TRIM2 in the TGF- $\beta 1$-stimulted A549 cells; these effects were reversed following transfection with the miR-369-3p inhibitor.

TRIM2 is the target gene of $m i R-369-3 p$. The binding sites between TRIM2 and miR-369-3p are shown in Fig. 6A. When the A549 cells were co-transfected with miR-369-3p mimics and TRIM2 WT vector, the Luc/R-Luc value was decreased (Fig. 6B). In addition, miR-369-3p overexpression decreased the mRNA (Fig. 6C) and protein (Fig. 6D) expression levels of TRIM2. 
A
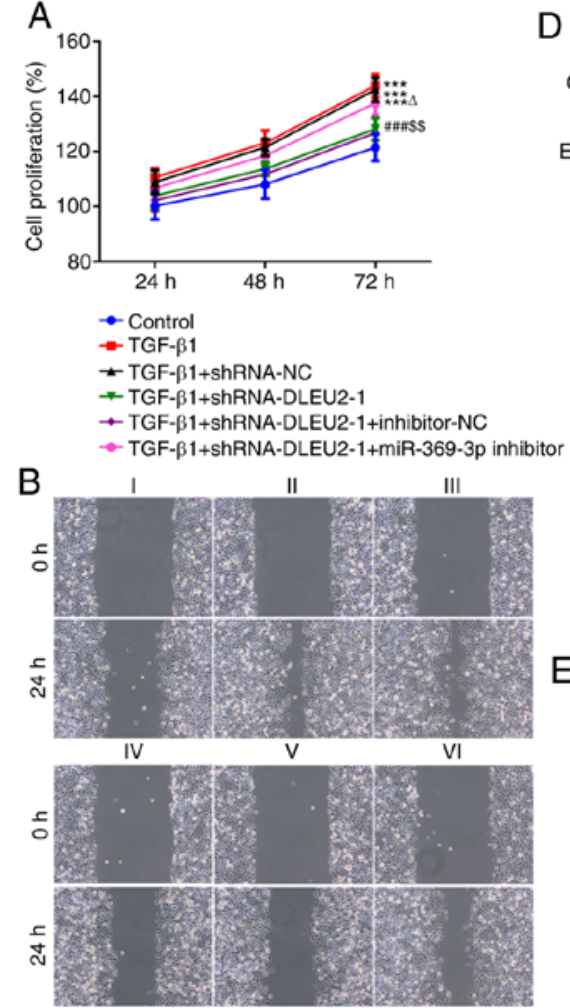

$\mathrm{C}$

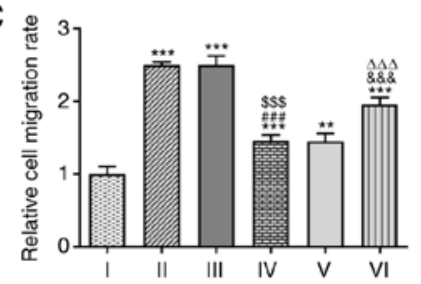

D
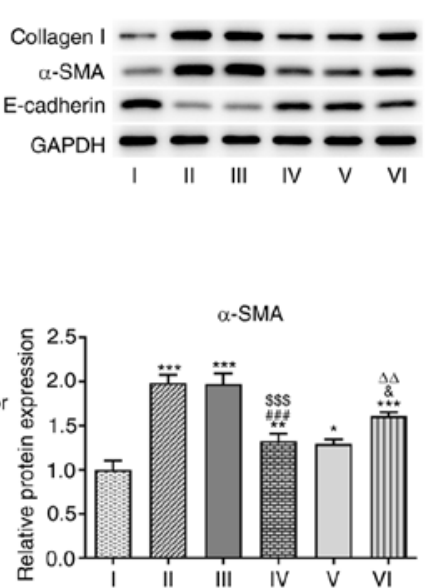

$\mathrm{E}$

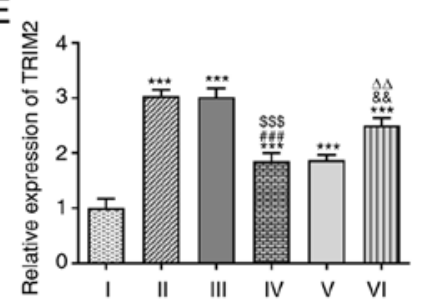

$\mathrm{F}$

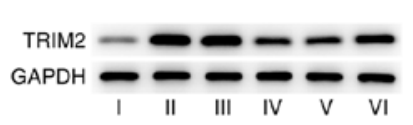

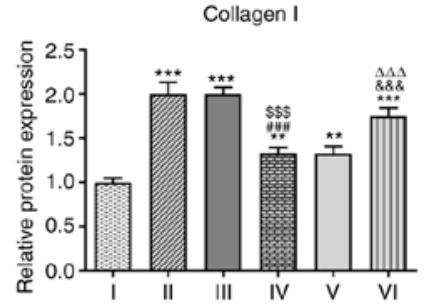

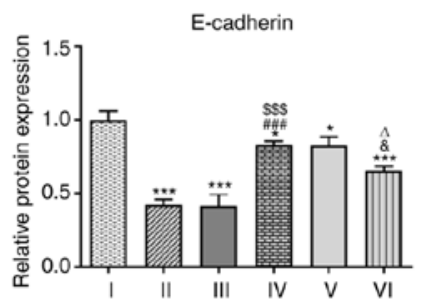

I $匚$ Control

II TGF- $\beta 1$

III $\square$ TGF- $\beta 1+$ ShRNA-NC

IV 图 TGF- $\beta 1+$ ShRNA-DLEU2-1

V ロ TGF- $\beta 1+$ shRNA-DLEU2-1+inhibitor-NC

VI 回 TGF- $\beta 1+$ shRNA-DLEU2-1+miR-369-3p inhibitor

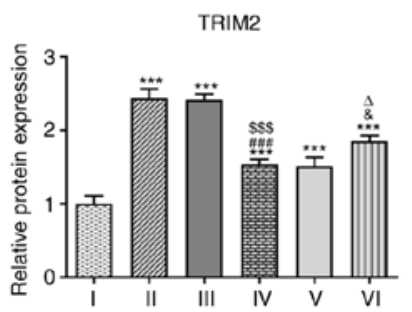

Figure 5. Knockdown of DLEU2 attenuates TGF- $\beta 1$-induced pulmonary epithelial fibrosis by regulating miR-369-3p. (A) The proliferation of TGF- $\beta 1$-stimulated A549 cells following transfection was analyzed by CCK-8 assay. (B and C) The migration of TGF- $\beta 1$-stimulated A549 following after transfection was analyzed by wound healing assay. (D) The expression of collagen I, $\alpha$-SMA and E-cadherin in T of TGF- $\beta 1$-stimulated cells following transfection was detected by western blot analysis. (E) The mRNA expression of TRIM2 in of TGF- $\beta 1$-stimulated A549 cells following transfection was detected by RT-qPCR. (F) The protein expression of TRIM2 in of TGF- $\beta 1$-stimulated A549 cells following transfection was detected by western blot analysis. ${ }^{*} \mathrm{P}<0.05,{ }^{* * *} \mathrm{P}<0.01$ and ${ }^{* * *} \mathrm{P}<0.001$ vs. control group. ${ }^{\# \# \#} \mathrm{P}<0.001$ vs. TGF- $\beta 1$ group; ${ }^{\mathrm{S} \$} \mathrm{P}<0.01$ and ${ }^{\$ \$ S} \mathrm{P}<0.001$ vs. TGF- $\beta 1+\operatorname{shRNA-NC}$ group; ${ }^{\circledR} \mathrm{P}<0.05$, ${ }^{\& \&} \mathrm{P}<0.01$ and ${ }^{\& \& \&} \mathrm{P}<0.001$ vs. TGF- $\beta 1+$ shRNA-DLEU2-1

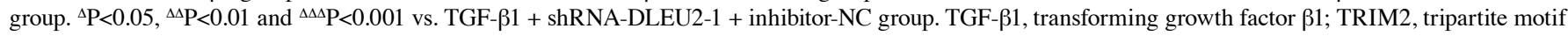
containing $2 ; \alpha$-SMA, $\alpha$ smooth muscle actin.

\section{Discussion}

IPF is a chronic and progressive pulmonary disease, characterized by the gradual increase of dyspnea, leading to respiratory failure, and the mortality rate is increasing $(16,17)$. A previous retrospective study analyzed a database of 135 patients with interstitial pneumonia confirmed by surgical lung biopsy, and reported that age was an important independent predictor (18). Previous studies have demonstrated that the regulation of gene expression plays an important role in the aging process $(19,20)$. lncRNAs have been found to be associated with both IPF and senescence $(21,22)$.

In the present study, DLEU2 expression was found to be increased in IPF tissues by analyzing 3 datasets from the GEO database. DLEU2 has been previously investigated in cancer. DLEU2 expression has been found to be increased in glioma tissues and cell lines, and the downregulation of DLEU2 has been shown to suppress the colony formation, migration and invasion of glioma cells (23). DLEU2 has also been found to be highly expressed in hepatocellular carcinoma (HCC) tissues, and to be associated with tumor size, vascular invasion and worse tumor stage, whereas the knockdown of DLEU2 reduces the proliferative, migratory and invasive abilities of HCC cells (24). In addition, DLEU2 expression has been shown to be increased in esophageal cancer tissues and DLEU2 knockdown suppresses the proliferation, migration and invasion of esophageal cancer cells, and promotes apoptosis by regulating the Bcl-2/Bax axis (25). In the present study, TGF- $\beta 1$-stimulated A549 cells were established as an in vitro model of IPF. Similar with the change and role of DLEU2 in a number of types of cancer, DLEU2 expression was also found to be increased in TGF- $\beta 1$-stimulated A549 cells and lung tissues from mice with BLM-induced fibrosis. The knockdown of DLEU2 inhibited the TGF- $\beta 1$-induced proliferation, migration and EMT of A549 cells, and attenuated BLM-induced pulmonary fibrosis in mice.

lncRNA is a competitive endogenous RNA with a miRNA recognition element, which can compete with mRNAs for the 
A

TRIM2: 5' UaAGAUAGA--AUGUAUUAUa 3

| ||$|:|||||||||$

hsa-miR-369-3p: 3' uuUCUAGUUGGUACAUAAUAa $5^{\prime}$

B

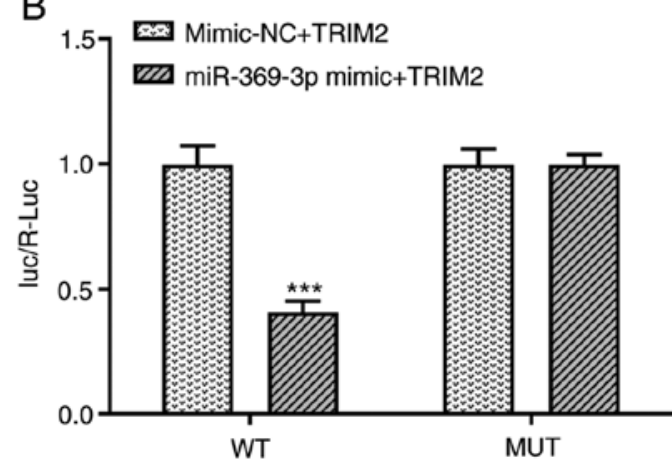

D

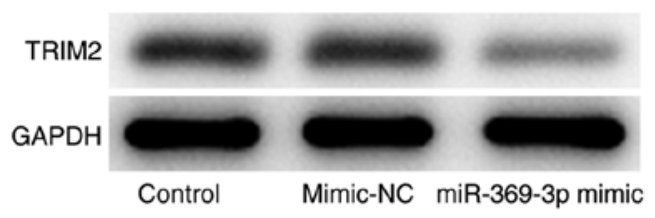

C
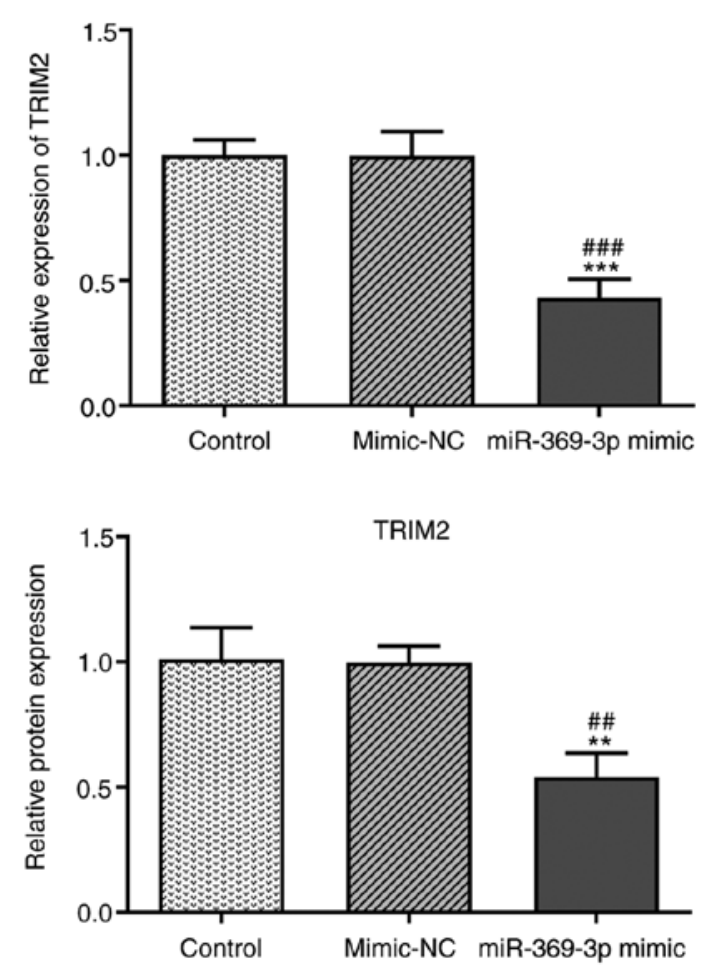

Figure 6. TRIM2 is the target gene of miR-369-3p. (A) Binding sites between miR-369-3p and TRIM2. (B) Luciferase reporter assay for the confirmation of direct binding relationship between miR-369-3p and TRIM2. ${ }^{* * *} \mathrm{P}<0.001$ vs. mimic-NC + TRIM2 WT group. (C) The mRNA expression of TRIM2 in A549 cells transfected with miR-369-3p mimic was detected by RT-qPCR. (D) The protein expression of TRIM2 in A549 cells transfected with miR-369-3p mimic was detected by western blot analysis. ${ }^{* *} \mathrm{P}<0.01$ and ${ }^{* * * *} \mathrm{P}<0.001$ vs. control group; ${ }^{\# \#} \mathrm{P}<0.01$ and ${ }^{\# \# \#} \mathrm{P}<0.001$ vs. mimic-NC group.

same miRNA response element, thus inhibiting the binding of miRNAs to mRNAs and affecting the regulatory effect of miRNAs on target genes (26). miR-369-3p expression has been found to be decreased in endometrioid adenocarcinoma tissues and miR-369-3p overexpression suppresses cell proliferation and migration in endometrioid adenocarcinoma (27). miR-369-3p expression has been shown to be notably increased in Hirschsprung's disease and the dysregulation of miR-369-3p has been shown to decrease the proliferation and migration of the SH-SY5Y and 293T cells (28). In addition, in a previous study, the expression of miR-369-3p was to be decreased and to be associated with a poor prognosis in patients with HCC. Functionally, miR-369-3p overexpression inhibited the viability and motility of HCC cells (29). miR-369-3p expression was decreased in the inflamed intestinal regions obtained from patients with inflammatory bowel disease and the overexpression of miR-369-3p alleviated the inflammatory response in response to lipopolysaccharide (30). Consistent with the findings of previous studies, the expression levels of miR-369-3p were also decreased in TGF- $\beta 1$-stimulated A549 cells and lung tissues from mice with BLM-induced fibrosis in the present study. The downregulation of miR-369-3p weakened the effect of DLEU2 knockdown on TGF- $\beta 1$-stimulated A549 cells and further promoted the TGF- $\beta 1$-induced proliferation, migration and EMT of A549 cells. In addition, TRIM2 was the target gene of miR-369-3p and TRIM2 expression was increased in TGF- $\beta 1$-stimulated A549 cells and lung tissues from mice with BLM-induced fibrosis.

A previous study indicated that TRIM2 promoted the growth, invasion and metastasis of colorectal cancer cells through EMT (10). In the present study, it was demonstrated that DLEU2 regulated TRIM2 by miR-369-3p, and it was thus hypothesized that TRIM2 may affect tumor metastasis through EMT. Herein, it was found that the downregulation of DLEU2 improved E-cadherin expression in TGF- $\beta 1$-stimulated A549 cells and lung tissues from mice with BLM-induced fibrosis.

In conclusion, DLEU2 expression was found to be increased in IPF tissues from the analysis of expression data downloaded from the GEO database. The expression levels of DLEU2 and TRIM2 were increased, while the expression levels of miR-369-3p were decreased in TGF- $\beta 1$-stimulated A549 cells and lung tissues from mice with BLM-induced fibrosis. The knockdown of DLEU2 suppressed IPD by increasing and decreasing the miR-369-3p and TRIM2 expression levels, respectively. These findings indicated that the negative modulation of DLEU2 may be a novel treatment strategy for IPF. In the future, the authors aim to confirm DLEU2 expression in lung tissues of patients with IPF and to explore the role of TRIM2 in IPF. In addition, the regulatory role of TRIM2 in IPF warrants further investigation. 


\section{Acknowledgements}

Not applicable.

\section{Funding}

This study was funded by the Natural Science Foundation of Hunan Province (grant no. 2019JJ80044).

\section{Availability of data and materials}

The datasets used and/or analyzed during the current study are available from the corresponding author on reasonable request.

\section{Authors' contributions}

DJ consulted the literature, and conceived and designed the study. HY conducted all the experiments and DL assisted HY in collecting the raw data. YX assisted HY in performing the statistical analysis. HY drafted the manuscript, which was reviewed and corrected by LJ. All authors read and approved the final manuscript.

\section{Ethics approval and consent to participate}

All the animal experiments were approved and supervised by the Animal Care and Use Committee and the Animal Ethics Committee at University of South China.

\section{Patient consent for publication}

Not applicable.

\section{Competing interests}

The authors declare they have no competing interests.

\section{References}

1. Caminati A, Madotto F, Cesana G, Conti S and Harari S Epidemiological studies in idiopathic pulmonary fibrosis: Pitfalls in methodologies and data interpretation. Eur Respir Rev 24 436-444, 2015

2. Chanda D, Otoupalova E, Smith SR, Volckaert T, De Langhe SP and Thannickal VJ: Developmental pathways in the pathogenesis of lung fibrosis. Mol Aspects Med 65: 56-69, 2019.

3. Meyer KC: Pulmonary fibrosis, part I: Epidemiology, pathogenesis, and diagnosis. Expert Rev Respir Med 11: 343-359, 2017.

4. Johnsson P, Lipovich L, Grandér D and Morris KV: Evolutionary conservation of long non-coding RNAs; Sequence, structure, function. Biochim Biophys Acta 1840: 1063-1071, 2014.

5. Sun C, Huang L, Li Z, Leng K, Xu Y, Jiang X and Cui Y: Long non-coding RNA MIAT in development and disease: A new player in an old game. J Biomed Sci 25: 23, 2018.

6. Wu W, Zhao Y, Gao E, Li Y, Guo X, Zhao T, He W and Zhang H: LncRNA DLEU2 accelerates the tumorigenesis and invasion of non-small cell lung cancer by sponging miR-30a-5p. J Cell Mol Med 24: 441-450, 2020

7. Liu W, Liu PC, Ma K, Wang YY, Chi QB and Yan M: LncRNA DLEU2 promotes tumour growth by sponging miR-337-3p in human osteosarcoma. Cell Biochem Funct 38: 886-894, 2020.

8. Wang B, Hang J, Li W and Yuan W: Knockdown of LncRNA DLEU2 inhibits cervical cancer progression via targeting miR-128-3p. Onco Targets Ther 13: 10173-10184, 2020.

9. Lu M, Chen W, Zhuang W and Zhan X: Label-free quantitative identification of abnormally ubiquitinated proteins as useful biomarkers for human lung squamous cell carcinomas. EPMA J 11: 73-94, 2020.
10. Cao H, Fang Y, Liang Q, Wang J, Luo B, Zeng G, Zhang T, Jing X and Wang X: TRIM2 is a novel promoter of human colorectal cancer. Scand J Gastroenterol 54: 210-218, 2019.

11. Qin Y, Ye J, Zhao F, Hu S and Wang S: TRIM2 regulates the development and metastasis of tumorous cells of osteosarcoma. Int J Oncol 53: 1643-1656, 2018.

12. Dong R, Liu M, Huang XX, Liu Z, Jiang DY, Xiao HJ, Geng J, Ren YH and Dai HP: Water-Soluble $\mathrm{C}_{60}$ protects against bleomycin-induced pulmonary fibrosis in mice. Int J Nanomedicine 15: 2269-2276, 2020.

13. Livak KJ and Schmittgen TD: Analysis of relative gene expression data using real-time quantitative PCR and the 2(-Delta Delta C(T)) method. Methods 25: 402-408, 2001.

14. Tang F, Li R, Xue J, Lan J, Xu H, Liu Y, Zhou L and Lu Y: Azithromycin attenuates acute radiation-induced lung injury in mice. Oncol Lett 14: 5211-5220, 2017.

15. Abdelfattah MS, Elmallah MIY, Ebrahim HY, Almeer RS, Eltanany RMA and Abdel Moneim AE: Prodigiosins from a marine sponge-associated actinomycete attenuate $\mathrm{HCl}$ /ethanol-induced gastric lesion via antioxidant and anti-inflammatory mechanisms. PLoS One 14: e0216737, 2019.

16. Cookson WO and Moffatt MF: Bedside to gene and back in idiopathic pulmonary fibrosis. N Engl J Med 368: 2228-2230, 2013.

17. Fernandez IE and Eickelberg O: New cellular and molecular mechanisms of lung injury and fibrosis in idiopathic pulmonary fibrosis. Lancet 380: 680-688, 2012.

18. Fell CD, Martinez FJ, Liu LX, Murray S, Han MK, Kazerooni EA, Gross BH, Myers J, Travis WD, Colby TV, et al: Clinical predictors of a diagnosis of idiopathic pulmonary fibrosis. Am J Respir Crit Care Med 181: 832-837, 2010

19. Baumgart M, Groth M, Priebe S, Savino A, Testa G, Dix A, Ripa R, Spallotta F, Gaetano C, Ori M, et al: RNA-seq of the aging brain in the short-lived fish N. furzeri-conserved pathways and novel genes associated with neurogenesis. Aging Cell 13: 965-974, 2014

20. Benayoun BA, Pollina EA and Brunet A: Epigenetic regulation of ageing: Linking environmental inputs to genomic stability. Nat Rev Mol Cell Biol 16: 593-610, 2015.

21. Grammatikakis I, Panda AC, Abdelmohsen K and Gorospe M: Long noncoding RNAs(lncRNAs) and the molecular hallmarks of aging. Aging (Albany NY) 6: 992-1009, 2014.

22. Huang C, Yang Y and Liu L: Interaction of long noncoding RNAs and microRNAs in the pathogenesis of idiopathic pulmonary fibrosis. Physiol Genomics 47: 463-469, 2015.

23. Xie Z, Li X, Chen H, Zeng A, Shi Y and Tang Y: The lncRNA-DLEU2/miR-186-5p/PDK3 axis promotes the progress of glioma cells. Am J Transl Res 11: 4922-4934, 2019.

24. Guo Y, Bai M, Lin L, Huang J, An Y, Liang L, Liu Y and Huang W: LncRNA DLEU2 aggravates the progression of hepatocellular carcinoma through binding. Biomed Pharmacother 118: 109272, 2019.

25. Lu T, Wang R, Cai $\mathrm{H}$ and Cui Y: Long non-coding RNA DLEU2 promotes the progression of esophageal cancer through miR-30e-5p/E2F7 axis. Biomed Pharmacother 123: 109650, 2020.

26. Li C, Wang Z, Zhang J, Zhao X, Xu P, Liu X, Li M, Lv C and Song X: Crosstalk of mRNA, miRNA, IncRNA, and circRNA and their regulatory pattern in pulmonary fibrosis. Mol Ther Nucleic Acids 18: 204-218, 2019.

27. Liu P, Ma C, Wu Q, Zhang W, Wang C, Yuan L and Xi X: MiR-369-3p participates in endometrioid adenocarcinoma via the regulation of autophagy. Cancer Cell Int 19: 178, 2019.

28. Pan W, Yu H, Zheng B, Gao Y, Li P, Huang Q, Xie C and Ge X: Upregulation of MiR-369-3p suppresses cell migration and proliferation by targeting SOX4 in Hirschsprung's disease. J Pediatr Surg 52: 1363-1370, 2017.

29. Xu Q and Liu K: MiR-369-3p inhibits tumorigenesis of hepatocellular carcinoma by binding to PAX6. J Biol Regul Homeost Agents 34: 917-926, 2020.

30. Scalavino V, Liso M, Cavalcanti E, Gigante I, Lippolis A, Mastronardi M, Chieppa M and Serino G: miR-369-3p modulates inducible nitric oxide synthase and is involved in regulation of chronic inflammatory response. Sci Rep 10: 15942, 2020.

This work is licensed under a Creative Commons Attribution-NonCommercial-NoDerivatives 4.0 International (CC BY-NC-ND 4.0) License. 